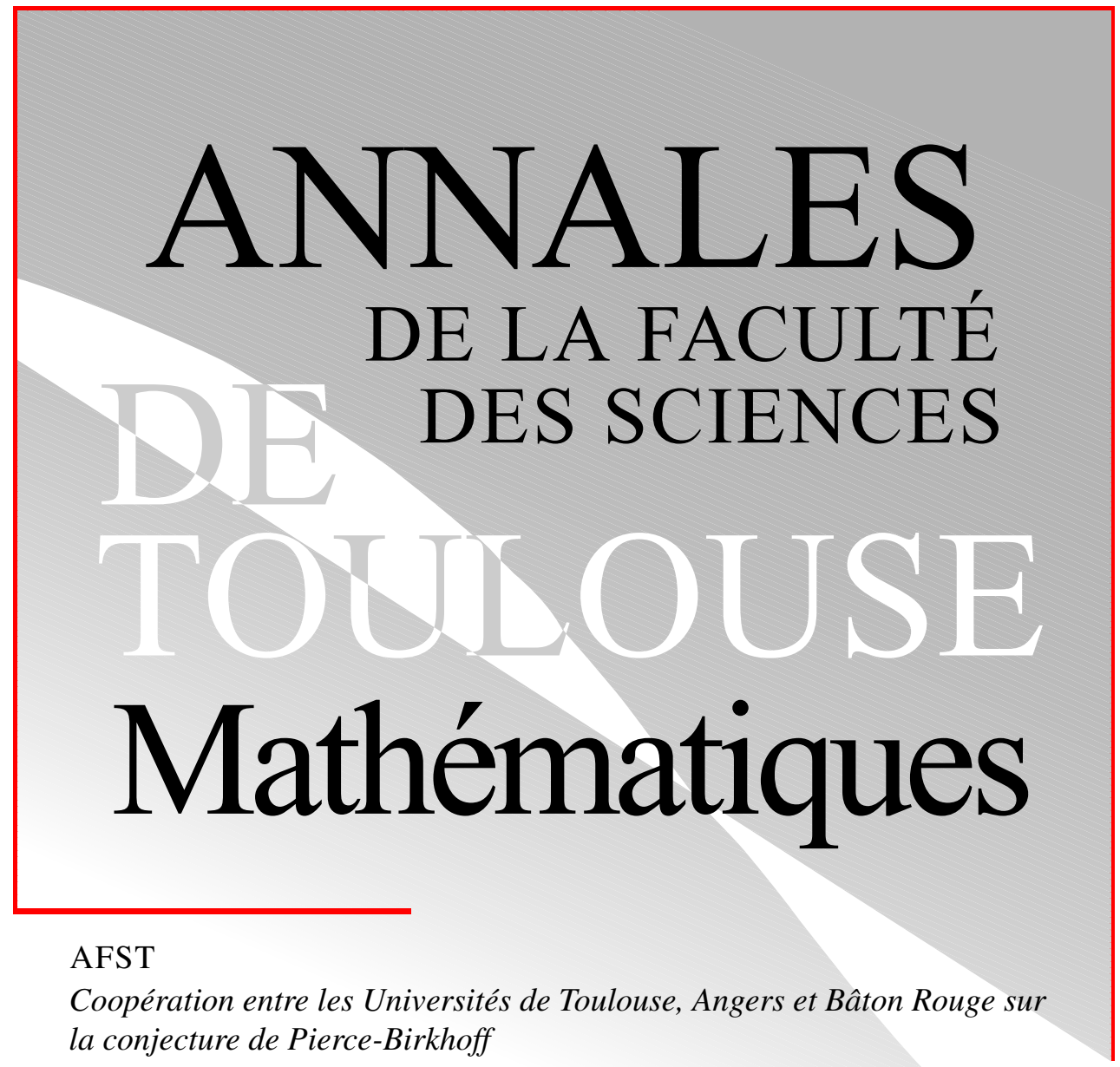

Tome XIX, nº S1 (2010), p. 1.

<http://afst.cedram.org/item?id=AFST_2010_6_19_S1_1_0>

(C) Université Paul Sabatier, Toulouse, 2010, tous droits réservés.

L'accès aux articles de la revue "Annales de la faculté des sciences de Toulouse Mathématiques » (http://afst.cedram.org/), implique l'accord avec les conditions générales d'utilisation (http://afst.cedram.org/ legal/). Toute reproduction en tout ou partie cet article sous quelque forme que ce soit pour tout usage autre que l'utilisation à fin strictement personnelle du copiste est constitutive d'une infraction pénale. Toute copie ou impression de ce fichier doit contenir la présente mention de copyright.

\title{
cedram
}

Article mis en ligne dans le cadre du

Centre de diffusion des revues académiques de mathématiques

http://www.cedram.org/ 


\section{Coopération entre les Universités de Toulouse, Angers et Baton Rouge sur la conjecture de Pierce-Birkhoff}

La conjecture de Pierce-Birkhoff est une des conjectures centrales dans le domaine des structures ordonnées et géométrie algébrique réelle. Elle affirme que toute fonction $f: \mathbb{R}^{n} \rightarrow \mathbb{R}$ polynomiale par morceaux peut être obtenue à partir de l'anneau de polynômes en $n$ variables en itérant les opérations de maximum et minimum.

Depuis une dizaine d'années, nous menons un projet de recherche commun entre les Universités d'Angers (F. Lucas, D. Schaub), Toulouse (M. Spivakovsky) et Baton Rouge (C. Delzell, J.J. Madden). Ce projet a pour but une résolution définitive de la conjecture de Pierce-Birkhoff. Une partie de la Conférence 2007 sur les Anneaux Ordonnés (les exposés de Delzell, Schaub et Spivakovsky et l'article de Wagner publié dans le présent volume) s'inscrit dans ce projet de collaboration. Nous espérons que la Conférence à Baton Rouge et la publication de ce Volume Spécial contribueront à une meilleure comprehension du problème et que d'autres conférences similaires seront organisées dans le futur, eventuellement à Toulouse ou à Angers. 